\title{
Lipoma of the Nasal Septum: A Case Report
}

\author{
Hesam Jahandideh ${ }^{1}$, Fatemeh Dehghani Firouzabadi ${ }^{2}$, Mohammad Dehghani Firouzabadi $^{3}$, Delaram Jan $^{4}$, Maryam Roomiani $^{5}$
}

\begin{abstract}
Aim: To diagnose a rare case of lipoma in nasal septum that causes nasal obstruction.

Background: Lipoma is one of the most common neoplasms in adults. Although lipoma of upper back, arms, upper thigh, buttock, and shoulders are common, lipoma of the nasal cavity, paranasal sinuses, or midface are rare due to lack of normal adipose tissue. Here, we present a 22-yearold man with lipoma on upper part of his nasal septum.

Case description: A 22-year-old man presented to our hospital with the chief complaint of nasal obstruction. On physical examination, he had significant septal deviation with obvious nasal deformity. Computed tomography without contrast revealed unusual septal thickness, and subsequent magnetic resonance imaging showed an amorphous heterogeneous fat content mass. The mass was excised using submucoperichondrial approach with no complication. No recurrence was seen after 6 months, and while nasal airway opened considerably, the apparent nasal deviation was alleviated to some degree.

Conclusion: Lipoma of the nasal septum is a rare presentation. While this mass may present itself as a common septal deviation, we should keep in mind rare causes of nasal obstruction other than deflected cartilages.

Clinical significance: Lipoma of nasal septum is not common in the midface, and it is hard to find and rare in nasal cavity due to scarce amount of fatty tissue that presents with nasal obstruction.

Keywords: Case report, Lipoma, Nasal septum.

Clinical Rhinology An International Journal (2019): 10.5005/jp-journals-10013-1355
\end{abstract}

\section{INTRODUCTION}

Lipoma is the most common soft tissue neoplasm in adults. It appears mostly in 40-50 years of age and is slightly more prevalent in males than in females. It accounts for differential diagnosis of nasopharynx mass as benign that is located more in upper back, shoulders, arms, buttocks, and upper thigh. ${ }^{1}$ The prevalence of this painless tumor is $1 \%$ in general population, they are not common in the midface, and it is hard to find and rare in paranasal sinuses or nasal cavity due to scarce amount of fatty tissue. ${ }^{2}$ Here, we report a rare case of nasal lipoma that is found on the nasal septum.

\section{Case Description}

A 22-year-old male presented to our hospital with left-sided nasal obstruction for more than 2 years. Patient's medical history including previous history of allergy or surgery was nonspecific. On physical examination, left-sided septal bulging, which was soft and compressible, was observed (Fig. 1). More careful inspection of upper part of septum revealed a distinct small round mass (Fig. 2). Computed tomography (CT) scan without contrast revealed a hypodense mass with $1.5 \mathrm{~cm}$ thickness (Fig. 3). Further evaluation with magnetic resonance imaging (MRI) to inspect any possible intracranial connection showed an amorphous heterogeneous $54 \times 8 \times 94 \mathrm{~mm}$ mass located in the left anterior part of the nasal septum. The mass was hyper signal in T2-weighted images and did not enhance after gadolinium injection, contrary to its overlying normal nasal mucosa (Figs 4 and 5). Under general anesthesia, mucoperichondrial flap was elevated using left hemitransfixion incision, and the tumor was excised completely. Histopathology report confirmed lipoma. Patient had no complications during or after surgery. We followed up the patient for 6 months. His nasal obstruction improved significantly, and the apparent nasal deviation was alleviated to some degree. No recurrence of the tumor was detected in the follow-up period.
${ }^{1}$ ENT and Head and Neck Research Center and Department, Firoozgar Hospital, Iran University of Medical Sciences, Tehran, Iran

${ }^{2-5}$ ENT and Head and Neck Research Center, The Five Senses Institute, Iran University of Medical Sciences, Tehran, Iran

Corresponding Author: Maryam Roomiani, ENT and Head and Neck Research Center, The Five Senses Institute, Iran University of Medical Sciences, Tehran, Iran, Phone: +98 9168618868, e-mail: maryamroomiani3@gmail.com

How to cite this article: Jahandideh H, Dehghani Firouzabadi F, Dehghani Firouzabadi M, et al. Lipoma of the Nasal Septum: A Case Report. Clin Rhinol An Int J 2019;12(1):35-37.

Source of support: Nil

Conflict of interest: None

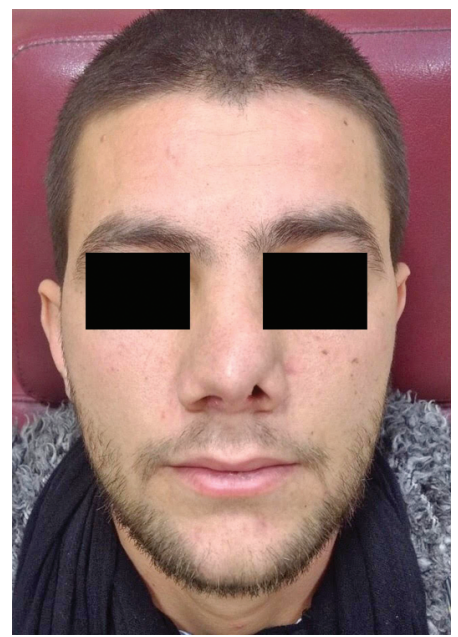

Fig. 1: Nasal deformity and deviation due to underlying septal mass

(-) The Author(s). 2019 Open Access This article is distributed under the terms of the Creative Commons Attribution 4.0International License (https://creativecommons. org/licenses/by-nc/4.0/), which permits unrestricted use, distribution, and non-commercial reproduction in any medium, provided you give appropriate credit to the original author(s) and the source, provide a link to the Creative Commons license, and indicate if changes were made. The Creative Commons Public Domain Dedication waiver (http://creativecommons.org/publicdomain/zero/1.0/) applies to the data made available in this article, unless otherwise stated. 


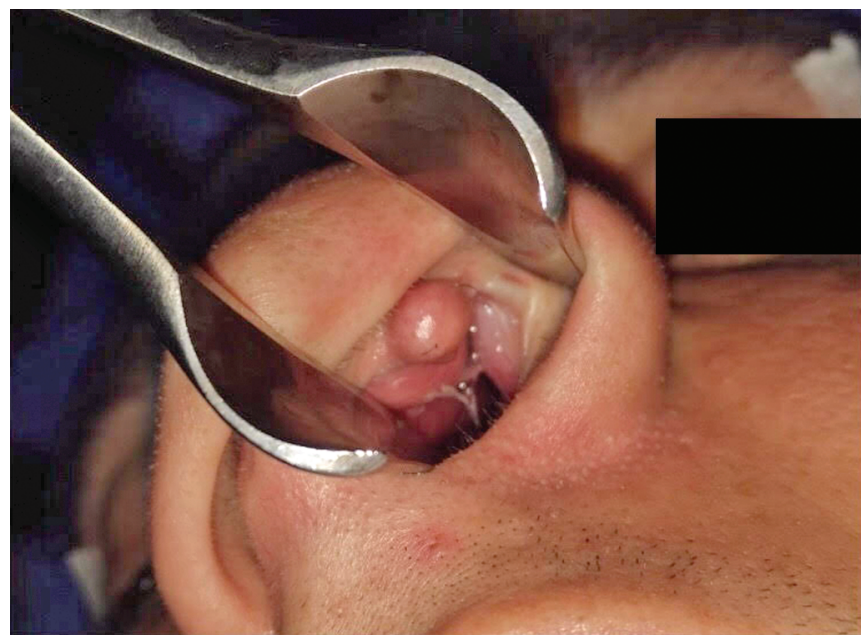

Fig. 2: More careful inspection of upper part of setup revealed a round mass

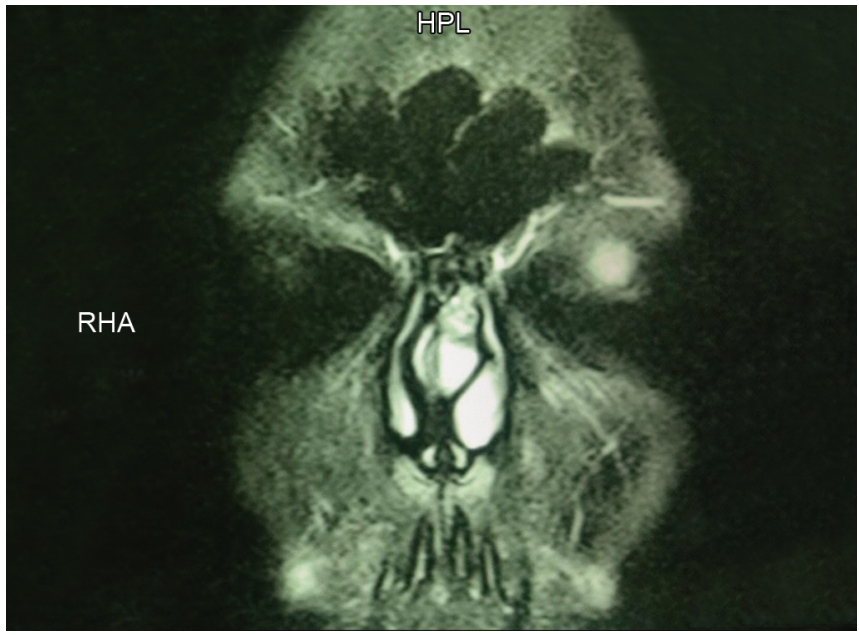

Fig. 4: T2-weighted MRI shows bizarre-shaped $54 \times 8 \times 94 \mathrm{~mm}$ hyper signal mass located in left anterior part of the nasal septum

\section{Discussion}

Lipoma is a benign slow-growing neoplasm that mostly consists of mature adapoid cells. In all, $13 \%$ of lipomas occur in head and neck in the posterior neck, chicks, tongue, floor of the mouth, and buccal sulcus. ${ }^{3,4}$ Lipoma of the nasal cavity is a rare one that is mostly reported in children as a single mass or a piece of a syndrome..$^{5-7}$ There are few reports of lipomas in different parts of nose including nasopharynx, vestibule, nasal dorsum, and inferior turbinate. ${ }^{4,8-11}$ Patients may be asymptomatic or like other masses occurring in sinuses and nasal cavity they may present with symptoms, including nasal obstruction, facial edema, tenderness, rupture, and hemorrhage. ${ }^{8,12-16}$

There have been reports of pediatric nasal lipoma and their associations with midline fascial defects and different syndromes. ${ }^{17}$ Pai syndrome has been described primarily in 1987 as a condition consisting of congenital nasal lipoma, midline cleft of upper lip, skin and nasal polyps and lipoma of central nervous system. ${ }^{6,18}$ Other reports indicated the nonsyndromic association of nasal lipoma and intracranial lipoma, especially in corpus callusum. ${ }^{14}$ In adults, however, the first case of nasal septal lipoma has been

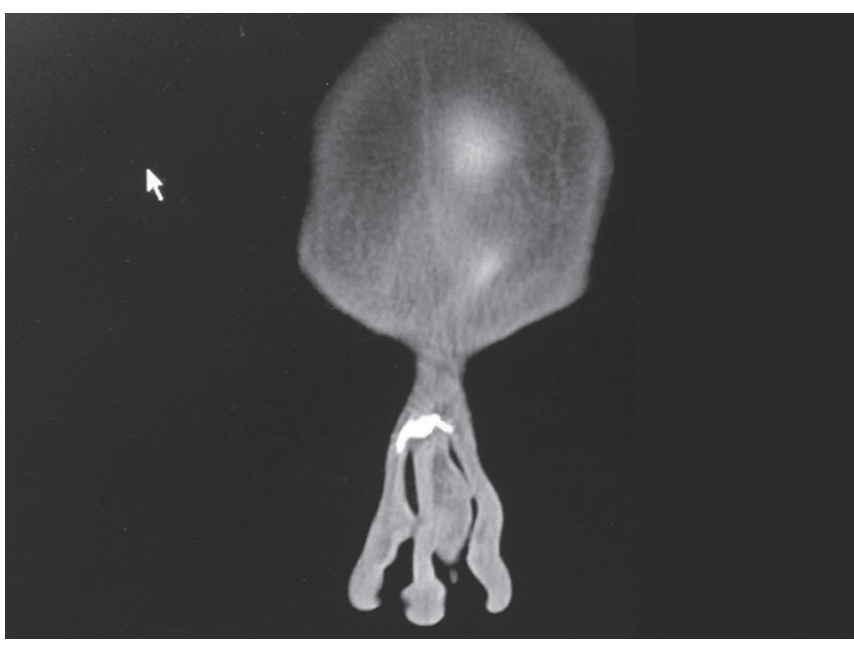

Fig. 3: Hypodense mass $54 \times 8 \times 94$ is nasal septum

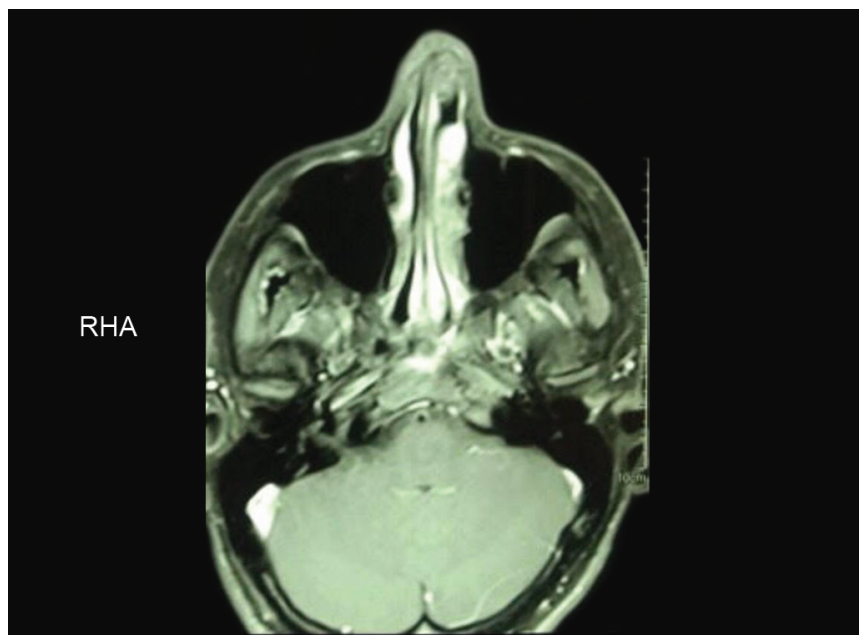

Fig. 5: IV contrast T1-weighted MRI. Non-enhancing mass in left anterior part of the nasal septum

reported in 2000 in a 21-year-old woman referring with unilateral nasal obstruction and posterior septal soft tissue mass. ${ }^{4}$

CT scan can reveal a hemogeneous mostly not encapsulated low-density mass, facilitating the diagnosis by showing the characteristics of fat tissue. ${ }^{19}$ It can also help in finding the possible intracranial extension and boney midline defect of face and skull base. Some authors suggested using routine imaging in all cases of pediatric midline nasal lipomas. ${ }^{5}$

In our study, nasal septal lipoma was reported in a 22-yearold man. Tumor removal was done using mucoperichondrial flap. Differential diagnoses of nasal lipoma are dermoid cysts, teratoma, glioma, encephalocele, and meningomyelocele, all of them may resemble a deviation if the septum is examined in less than a meticulous way. ${ }^{17}$

\section{Conclusion}

Lipoma of the nasal septum is a rare presentation. We report a case of nasal septal lipoma with nasal obstruction that could easily pass as a septal deviation without a conscientious examination. Performing imaging studies before septoplasty in cases of nasal 
obstruction with questionable physical examination could lead to precise diagnosis.

\section{Clinical Significance}

Lipoma of nasal septum is not common in the midface, and it is hard to find and rare in nasal cavity due to scarce amount of fatty tissue that presents with nasal obstruction.

\section{References}

1. Enzinger FM, SWW. Soft tissue tumors. 3rd ed., 1995.

2. Fu YS, Perzin KH. Non-epithelial tumors of the nasal cavity, paranasal sinuses and nasopharynx: a clinicopathologyic study. VIII. Adipose tissue tumors (lipoma and liposarcoma). Cancer 1977;40(3):1314-1317. DOI: 10.1002/1097-0142(197709)40:33.0.co;2-o.

3. Ayasaka N, Chino Jr T, Chino T, et al. Infiltrating lipoma of the mental region: report of a case. Br J Oral Maxillofac Surg 1993;31(6):388-390. DOI: 10.1016/0266-4356(93)90196-4.

4. Takasaki K, Yano H, Hayashi T, et al. Nasal lipoma. J Laryngol Otol 2000;114(3):218-220. DOI: 10.1258/0022215001905166.

5. Abdollahi Fakhim S, Bayazian G, Notash R. Nasal septal lipoma in a child: Pai syndrome or not? Int J Pediatr Otorhinolaryngol 2014;78(4):697-700. DOI: 10.1016/j.ijporl.2014.01.027.

6. Szeto $C$, Tewfik TL, Jewer $D$, et al. Pai syndrome (median cleft palate, cutaneous nasal polyp, and midline lipoma of the corpus callosum): a case report and literature review. Int J Pediatr Otorhinolaryngol 2005;69(9):1247-1252. DOI: 10.1016/j.ijporl.2005.01.038.

7. Azurdia J, Burke L, Laub Jr D. Pai syndrome: median cleft lip, corpus callosum lipoma, and fibroepithelial skin tag. Eplasty 2014;14:ic7.
8. Oddie JW, Applebaum EL. Lipoma of the nasopharynx. Arch Otolaryngol (Chicago, Ill: 1960) 1982;108(1):57. DOI: 10.1001/ archotol.1982.00790490059018.

9. Grybauskas V, Shugar M. Nasopharyngeal lipoma. Laryngoscope 1983;93(3):362-363. DOI: 10.1288/00005537-198303000-00022.

10. Abulezz T, Allam K. Nasal subcutaneous lipoma, a case report. Rhinol 2008;46(2):151-152.

11. Mahmood NS. An extremely rare case of a nasal turbinate lipoma. Dentomaxillofac Radiol 2010;39(1):64. DOI: 10.1259/dmfr/65109233.

12. Goldstein MA. Lipoma of the maxillary antrum. Laryngoscope 1915;25(3):142-144. DOI: 10.1288/00005537-191503000-00004.

13. Silbernagel CE. Lipoma of the maxillary antrum. Laryngoscope 1938;48(6):427-442. DOI: 10.1288/00005537-193806000-00010.

14. Shah A, Rai S, Goel A. Corpus callosal lipoma extending as nasal encephalocoel/cranial lipomeningocoel. J Clin Neurosci 2017;45:157159. DOI: 10.1016/j.jocn.2017.08.022.

15. Pryor SG, Orvidas LJ, Moore EJ. Lipoma of the nasal dorsum: an unusual presentation of a common neoplasm. Otolaryngol Head Neck Surg 2007;136(1):151-152. DOI: 10.1016/j.otohns.2005.11.029.

16. Puri ND, Vaid A, Sawhney KL. Fibrolipoma of the nasopharynx. J Indian Med Assoc 1979;72(9):215-216.

17. Hollis LJ, Bailey CM, Albert DM, et al. Nasal lipomas presenting as part of a syndromic diagnosis. J Laryngol Otol 1996;110(3):269-271. DOI: $10.1017 / \mathrm{s} 0022215100133389$.

18. Morice A, Galliani E, Amiel J, et al. Diagnostic criteria in Pai syndrome: results of a case series and a literature review. Int J Oral Maxillofac Surg 2019;48(3):283-290. DOI: 10.1016/j.ijom.2018.08.010.

19. Tien RD, Hesselink JR, Chu PK, et al. Improved detection and delineation of head and neck lesions with fat suppression spin-echo MR imaging. AJNR Am J Neuroradiol 1991;12(1):19-24. 